\title{
OCD-Like Behaviors Caused by a Neuropotentiating Transgene Targeted to Cortical and Limbic D1+ Neurons
}

\author{
Keith M. Campbell, ${ }^{1}$ Luis de Lecea, ${ }^{2}$ Diana M. Severynse, ${ }^{3}$ Marc G. Caron, ${ }^{3}$ Michael J. McGrath, ${ }^{1}$ \\ Sheldon B. Sparber, ${ }^{1}$ Li-Yan Sun, ${ }^{1}$ and Frank H. Burton ${ }^{1}$ \\ 1Department of Pharmacology, University of Minnesota, Minneapolis, Minnesota 55455, 2Department of Molecular \\ Biology, The Scripps Research Institute, La Jolla, California 92037, and ${ }^{3}$ Howard Hughes Medical Institute, Department of \\ Cell Biology, Duke University Medical Center, Durham, North Carolina 27710
}

To study the behavioral role of neurons containing the D1 dopamine receptor (D1+), we have used a genetic neurostimulatory approach. We generated transgenic mice that express an intracellular form of cholera toxin (CT), a neuropotentiating enzyme that chronically activates stimulatory $G$-protein $\left(G_{s}\right)$ signal transduction and CAMP synthesis, under the control of the D1 promoter. Because the D1 promoter, like other CNSexpressed promoters, confers transgene expression that is regionally restricted to different D1+CNS subsets in different transgenic lines, we observed distinct but related psychomotor disorders in different D1CT-expressing founders. In a D1CT line in which transgene expression was restricted to the following D1 + CNS regions-the piriform cortex layer II, layers II-III of somatosensory cortical areas, and the intercalated nucleus of the amygdala-D1CT mice showed normal CNS and D1+ neural architecture but increased cAMP content in whole extracts of the piriform and somatosensory cortex. These mice also exhibited a constellation of compulsive behavioral abnormalities that strongly resembled human cortical-limbic-induced compulsive disorders such as obsessive-compulsive disorder (OCD). These compulsive behaviors included episodes of perseverance or repetition of any and all normal behaviors, repetitive nonaggressive biting of siblings during grooming, and repetitive leaping. These results suggest that chronic potentiation of cortical and limbic D1+ neurons thought to induce glutamatergic output to the striatum causes behaviors reminiscent of those in human cortical-limbic-induced compulsive disorders.

Key words: transgenic mice; cholera toxin; dopamine; D1 receptor; obsessive-compulsive disorder; cAMP; G-proteins; stereotypy; piriform; somatosensory; intercalated nucleus
Functional errors in neurons that respond to dopamine may underlie psychomotor and psychiatric diseases, including parkinsonism, schizophrenia, depression, drug addiction, Tourette's syndrome, and obsessive-compulsive disorder (OCD) (Bernheimer et al., 1973; Brown and Gershon, 1993; Ritz and Kuhar, 1993; McDougle et al., 1994; Bachus and Kleinman, 1996). Among the dopaminoceptive neurons, those that express the D1 dopamine receptor subtype $(\mathrm{D} 1+)$ are widely distributed in the CNS, and regionally localized subsets of D1+ neurons are thought to regulate motor function, volition, emotive behavior, memory, and metabolic homeostasis selectively (Levey et al., 1993; Bergson et al., 1995).

Because systemic or stereotaxic manipulation of D1+ neurons cannot be restricted to widespread but single cortical layers or

\footnotetext{
Received Nov. 20, 1998; revised March 16, 1999; accepted March 23, 1999.
}

This work was supported by National Institutes of Health Training Grant T32DA07097 (K.M.C.) and Research Grants R03MH53553 (F.H.B.), R37DA04979 (S.B.S.), and PO1DA08131 (S.B.S.), by research grants from the Howard Hughes Medical Institute (M.G.C.) and the Tourette's Syndrome Association (F.H.B.), and by the Jeff Sutton Memorial Young Investigator Award from the National Alliance for Research on Schizophrenia and Depression and the Rochester Area Alliance for the Mentally Ill (F.H.B.). We thank T. Walseth, L. Bertrand, A. Burd, and P. Law for technical assistance, R. Rohland for helpful discussion and technical assistance, and U. Campbell and E. Matro for assistance in preparing this manuscript.

Correspondence should be addressed to Dr. Frank H. Burton, Department of Pharmacology, University of Minnesota, 3-249 Millard Hall, 435 Delaware Street Southeast, Minneapolis, MN 55455.

Dr. Severynse's present address: Proctor and Gamble Corporation, Miami Valley Laboratories, 11810 East Miami River Road, Ross, OH 45061.

Dr. Sun's present address: Wayne Hughes Institute, 2657 Patton Road, Roseville, MN 55113.

Copyright (C) 1999 Society for Neuroscience $\quad 0270-6474 / 99 / 195044-10 \$ 05.00 / 0$ several CNS regions simultaneously, transgenic approaches to study the behavioral contribution of regional subsets of D1+ neurons may be useful. This is because transgene expression using neuron subtype-specific promoters is commonly regionally restricted to different CNS subsets of the promoter-expressing neurons in different lines of transgenic mice. This phenomenon of regional restriction of transgene expression has been used to study region-specific transgenic or gene knock-out effects (Bach et al., 1995; Mayford et al., 1995; Rotenberg et al., 1996; Tsien et al., 1996a,b). Similarly, the human D1 receptor promoter confers $\mathrm{D} 1+$ neuron-specific expression of a lac $Z$ transgene to different D1+ CNS subsets in different D1-lacZ transgenic lines (Severynse et al., 1995) and thus may be useful for transgenically manipulating the function of regional subsets of D1+ neurons.

Furthermore, direct transgenic modulation of neuron signal transduction may have greater duration and efficacy than does pharmacological modulation of receptors, because signal transduction is the means by which concerted actions on many different membrane receptors are integrated into permanent changes in neuron activity. Chronic transgenic modulation of neuron signal transduction has been achieved recently using a dominantnegative variant of protein kinase A in mice (Abel et al., 1997) and an activated form of the stimulatory G-protein $\left(\mathrm{G}_{\mathrm{s}}\right)$ in Drosophila (Connolly et al., 1996). Similarly, a transgene encoding the intracellular enzymatic subunit of cholera toxin (CT) that chronically stimulates $\mathrm{G}_{\mathrm{s}}$ activity, cAMP levels, and cAMPdependent cellular changes (Burton et al., 1991; Zeiger et al., 1997) has been used to potentiate neural activity in mice chron- 
ically (Burton et al., 1998). Using such transgenes to stimulate chronically the excitability of entire neurons, rather than to stimulate subsets of their receptors, may contribute to our understanding of the behavioral role of biochemically defined neuron subtypes.

Here we investigated the behavioral consequences of transgenic stimulation of regional subpopulations of D1+ neurons by expressing the CT transgene from the D1 promoter in "D1CT" transgenic mice. This study suggests that chronic potentiation of $\mathrm{D} 1+$ neurons within subsets of the cortex and amygdala known to induce orbitofrontal activity and efferent glutamatergic neurotransmission to the striatum induces complex compulsive behaviors in mice that resemble those of human cortical-limbicinduced compulsive disorders. This study also indicates that novel information about the molecular neuroanatomical basis of behavior can be obtained by transgenic neurostimulation.

\section{MATERIALS AND METHODS}

Generation of D1CT transgenic mice. The D1-lacZ plasmid (Severynse et al., 1995), which consists of the lac $Z$ reporter plasmid pNASS- $\beta$ (Clontech, Palo Alto, CA) fused to the $6.5 \mathrm{~kb}$ promoter region of the human D1 gene, was used to create the D1CT transgene. A $3.5 \mathrm{~kb}$ internal Not I fragment of D1-lacZ containing the lac $Z$ gene cassette was excised and replaced with a $0.6 \mathrm{~kb}$ PCR-amplified Not I CT gene cassette. The CT cassette was amplified using GHCT plasmid (Burton et al., 1991) as a template and sequence-confirmed before cloning. For embryo microinjection, the $7.5 \mathrm{~kb}$ D1CT gene was removed from the plasmid by SalI plus partial EcoRI digestion. D1CT transgene DNA was microinjected at 700 molecules per pronucleus into 200 fertilized Balb/c $\times \mathrm{C} 57 \mathrm{Bl} / 6$ hybrid eggs. Surviving eggs were implanted into pseudopregnant host mothers as described previously (Burton et al., 1991, 1998; Wogensen et al., 1993).

After being generated, D1CT transgenic mice and nontransgenic littermates were housed in groups of two to five in a temperaturecontrolled room and were kept on a 12:12 hr light/dark cycle. Experiments were conducted during the light phase of the cycle. The mice had access to food and water ad libitum. Care was taken to ensure that the mice used in this study received no unnecessary discomfort. Animals were maintained and studies were performed in accordance with the Animal Welfare Act and the NIH Guide for the Care and Use of Laboratory Animals, under the approval of the University of Minnesota Institutional Animal Care and Use Committee. The University of Minnesota animal facility is fully accredited by the American Association for the Accreditation of Laboratory Animal Care.

Reverse transcriptase-PCR. Poly $\left(\mathrm{A}^{+}\right)$RNA was extracted from frozen whole brain or brain hemispheres using the Quick Prep Micro mRNA Purification Kit (Pharmacia, Piscataway, NJ), and cDNA was prepared from $1.6 \mu \mathrm{g}$ of poly $\left(\mathrm{A}^{+}\right)$RNA using Moloney murine leukemia virus reverse transcriptase (Boehringer Mannheim, Indianapolis, IN). The reverse transcriptase (RT) product was PCR-amplified with AmpliTaq polymerase (Perkin-Elmer, Emeryville, CA) using primers designed to amplify specifically a 600 bp DNA fragment comprising the cholera toxin A1 subunit gene's open reading frame. DNA was visualized by agarose gel electrophoresis and ethidium bromide staining.

In situ hybridization/coimmunocytochemistry. Mice were intracardially perfused with $4 \%$ paraformaldehyde in $0.1 \mathrm{~m}$ phosphate, $\mathrm{pH} 7.4(4 \% \mathrm{PF}$ solution). Brains were post-fixed in $4 \% \mathrm{PF}$ solution for $12 \mathrm{hr}$ at $4^{\circ} \mathrm{C}$ and then placed in $4 \%$ PF solution with $30 \%$ sucrose overnight at room temperature. The brains were frozen, and $25-\mu \mathrm{m}$-thick sections were collected in cryoprotectant solution (30\% glycerol, $30 \%$ ethylene glycol, and $0.1 \mathrm{M}$ PBS). Free-floating CNS sections were subjected to combined immunocytochemistry (ICC) with in situ hybridization (ISH) as described previously (de Lecea et al., 1997). ${ }^{35}$ S-Uridine 5 '-triphosphate(DuPont NEN, Boston, MA) labeled CT-specific antisense and sense (negative control) riboprobes were prepared by in vitro transcription of a CT ORF-containing pGEM-11Zf (Promega, Madison, WI) plasmid DNA using T7 or T3 polymerase (Ambion, Austin, TX). Rat monoclonal anti-human D1 antiserum was supplied by Research Biochemicals (Natick, MA) and was used at a 1:500 dilution. ISH results were independently confirmed on mounted instead of free-floating CNS sections (data not shown), as described previously (Severynse et al., 1995).

cAMP radioimmunoassay. Tissue containing piriform and somatosen- sory cortex was dissected within $2.5 \mathrm{~min}( \pm 8 \mathrm{sec})$ after decapitation under inhalant anesthesia and immediately homogenized in $500 \mu \mathrm{l}$ of ice-cold $0.5 \mathrm{~m}$ perchloric acid. The homogenized samples were spun at $12,000 \times g$ for $10 \mathrm{~min}$ at $4^{\circ} \mathrm{C}$, and the resulting pellets were used for protein concentration quantification using a Lowry assay. The supernatants were neutralized by adding $140 \mu \mathrm{l}$ of ice-cold $2 \mathrm{M}$ potassium bicarbonate, and aliquots were diluted 1:2000 with water. The $\left[{ }^{125} \mathrm{I}\right]-$ labeled cAMP radioimmunoassay was performed as described previously (Walseth et al., 1989), using an antibody described previously (Gettys et al., 1990). The cAMP content of the homogenates was calculated from a standard curve and was expressed as femtomoles of cAMP per milligram of protein.

Quantification of biting behavior. Mice were video-recorded in their home cage. One D1CT mouse (D1CT-7 strain) and one control nontransgenic littermate per cage were continually observed in sequential 15 sec windows for $28 \mathrm{~min}$, resulting in 112 total observation periods per animal. Periods in which either a distress vocalization was heard or the observed mouse had its snout in contact with the other mouse were scored blindly and as separate behavioral events for that period. The "percent vocalization" was calculated as the number of periods in which both a vocalization was heard and the observed mouse had its snout in contact with the other mouse divided by the total number of periods in which a vocalization was heard. The observations in this assay were performed blindly with respect to the transgenic status of the mouse.

Resident-intruder aggression assay. "Resident" male D1CT mice (D1CT-7 strain) or male control nontransgenic littermates were housed alone for 2 weeks without a change of bedding to establish residency. Male CB6 (Balb/c $\times$ C57Bl/6) or male C57Bl/6 "intruder" mice were then placed into the resident cage. The number of times that a resident mouse attacked the intruder mouse was counted during the first $3 \mathrm{~min}$ after introduction of the intruder, as well as the number of seconds until the first attack. Intruder strain had no significant effect on the number of attacks or the attack latency by either D1CT or nontransgenic mice using repeated measures ANOVA. Therefore, the data were collapsed across intruder strain. The observations in this assay were performed blindly with respect to the transgenic status of the mouse.

Time-sampling assay of stereotypic behavior. D1CT mice (D1CT-7 strain) or control nontransgenic littermates were individually placed into a clean Plexiglas cage with no food, water, or bedding. Each mouse was observed blindly with respect to transgenic status for $10 \mathrm{sec}$ windows every $10 \mathrm{~min}$ for $90 \mathrm{~min}$. Any behavior was scored as "stereotypic" if it lasted at least 3 consecutive seconds during the $10 \mathrm{sec}$ window of observation (Fray et al., 1980). Multivariate ANOVA (MANOVA) was performed on the predicted dopaminergically induced behaviors consisting of the dependent variables locomotion, rear, sniff, gnaw, groom, and leap. If MANOVA outcomes were significant $(p<0.05)$, then ANOVA or $t$ test analysis of each variable independently was justified.

Behavioral waveform analysis of long duration and repetitive behaviors. Paired D1CT mice (D1CT-7 strain) and control nontransgenic littermates were video-recorded beginning $20 \mathrm{~min}$ after introduction into a new cage. All behaviors in which the paired mice engaged for $30 \mathrm{~min}$ were entered in real time, and their durations were individually measured and analyzed, using EthoMac software (Campbell et al., 1998). Waveform displays of the first $15 \mathrm{~min}$ were generated by importing EthoMac data into CA-Cricket Graph III (Computer Associates International). The mean duration of either all behaviors, consisting of repeatedly reinitiated $(\geq 2 \times)$ two-state behavioral sequences and single behaviors, or of simple stationary (one-state) behaviors was calculated from the EthoMac output of individual behavioral durations. The observations in this assay were performed blindly with respect to the transgenic status of the mouse.

\section{RESULTS}

\section{Generation of D1CT transgenic mice}

$\mathrm{CT}$ has been used for decades as a pharmacological research tool to potentiate neuronal activity chronically. Unlike receptorinduced changes, CT's effects are not reversed by feedback mechanisms (Burton et al., 1991, 1998; Cunningham and Kelley, 1993; Geller at al., 1993; Speigel, 1996; Zeiger et al., 1997). However, only the transgenic form of CT can be neuron subtype-selective. To investigate the behavioral role of $\mathrm{D} 1+$ neuron subpopulations, we generated mice that express the neurostimulatory CT transgene specifically in D1+ cells. To generate the D1CT transgene, 


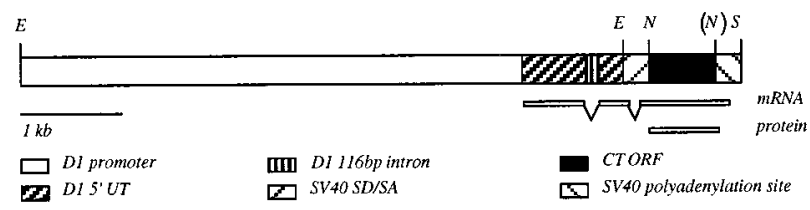

Figure 1. The human D1 dopamine receptor promoter-cholera toxin (D1CT) fusion transgene. E, EcoRI; N, NotI; $(N), N o t \mathrm{I}$ site deleted during cloning; $O R F$, open reading frame (coding sequence); $S$, SalI; $S D / S A$, splice donor/splice acceptor sites; $U T$, untranslated region.

we joined a CT gene cassette containing the portion of the operon for Vibrio cholerae holotoxin that encodes its noncytotoxic, enzymatically active intracellular subunit A1 to the promoter region of the human dopamine D1 receptor gene (Fig. 1).

Of 63 mice resulting from D1CT transgene injections, 6 contained the D1CT transgene (data not shown). This represented the expected percentage based on previous microinjections, suggesting that the transgene induced no embryonic lethality. These six founder mice were healthy at birth and remained viable throughout adulthood. Four of the founders were behaviorally normal. The remaining two founders (D1CT-11 and D1CT-7) exhibited pronounced to extreme psychomotor behavioral abnormalities. The most severely affected founder (D1CT-11) exhibited hyperlocomotion as well as extreme hyperreactivity ("popcorn behavior") in response to novel visual or auditory stimuli or to the introduction and subsequent advances of potential mates. This latter behavior precluded subsequent breeding of this female. The other affected D1CT founder, D1CT-7, exhibited hyperlocomotion as well as other psychomotor abnormalities described below. This male successfully mated and produced subsequent generations of similarly affected heterozygous transgenic progeny and behaviorally normal nontransgenic littermates.

\section{CT RNA is expressed in the CNS of behaviorally affected D1CT mice}

To determine whether the psychomotor behavioral abnormalities exhibited by the D1CT-11 and D1CT-7 strains were associated with D1CT transgene expression, we used RT-PCR analysis to test for the presence of CT mRNA transcripts in the brain of the infertile, affected D1CT-11 founder and of an F1 transgenic offspring of the affected D1CT-7 founder (Fig. 2), as well as of F1 transgenic mice of two unaffected D1CT strains (data not shown). CT transcripts were detected only in the two behaviorally affected transgenic strains, indicating that D1CT transgene expression, rather than insertional mutagenesis, is the most likely cause of their behavioral abnormalities. Moreover, the behavioral abnormalities in these two strains consisted of distinct but overlapping psychomotor symptoms, suggesting that they were caused by differential restriction of transgene expression to distinct subsets of $\mathrm{D} 1+$ neurons.

\section{CT RNA expression is regionally restricted in the CNS of D1CT mice}

In mice and rats, D1 receptor mRNA and protein colocalize in unique CNS distributions that include, but are not restricted to, the basal ganglia, the intercalated nucleus of the amygdala, and the contiguous piriform and somatosensory cortex (Fremeau et al., 1991; Weiner et al., 1991; Levey et al., 1993; Ariano and Sibley, 1994). Previous studies of D1-lacZ mice confirmed that transgene mRNA and protein expression colocalized with D1 protein immunoreactivity in the CNS, although from-line-to-line expression was regionally restricted to different D1+ CNS areas

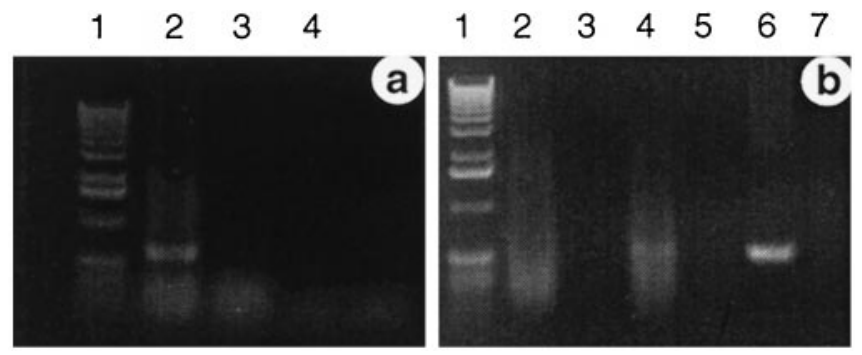

Figure 2. Detection of cholera toxin mRNA in brain extracts of affected D1CT mice. $a$, RT-PCR of affected D1CT-11 mouse brain poly $\left(\mathrm{A}^{+}\right)$ RNA. Lane 1, Kilobase ladder DNA size marker; lane 2, RT included (+RT); lane 3, RT omitted (-RT); lane 4, RNA omitted (-RNA). b, RT-PCR of nontransgenic (control) littermate and affected D1CT-7 mouse brain poly $\left(\mathrm{A}^{+}\right)$RNA. Lane 1, Kilobase ladder DNA size marker; lane 2, control, +RT; lane 3, control, - RT; lane 4, D1CT-7, +RT; lane 5, D1CT-7, - RT; lane 6, D1CT-7 genomic DNA template (positive control); lane $7,-$ RNA. CT mRNA is detected in the affected D1CT-11 and D1CT-7 mouse brain extracts as a 600 bp RT-PCR fragment ( $a$, lane $2 ; b$, lane 4 ) identical in size to a positive control CT genomic DNA PCR fragment $(b$, lane 6$)$.

(Severynse et al., 1995). To confirm faithful D1CT transgene expression and identify the extent of its regional restriction, we similarly performed ISH and ICC colocalization of CT mRNA and D1 protein on CNS sections from D1CT mice (D1CT-7 strain) and nontransgenic controls (Fig. 3). This showed that all CNS regions expressing $\mathrm{CT}$ also coexpressed D1, that CT and D1 were coexpressed in diagnostic D1+ CNS distributions, and that $\mathrm{CT}$ expression was consistently regionally restricted in this transgenic strain to a subset of cortical and amygdalar D1+ regions. These CT+ and D1 + CNS regions, listed in order of greatest to least CT ISH intensity, were the piriform cortex layer II, the intercalated nucleus of the amygdala, and layer II-III of the somatosensory cortical areas [including the insular cortex, the secondary (S2) somatosensory cortex, and the primary (S1) somatosensory cortex] (Fig. 3). Furthermore, the CT hybridization pattern in piriform layer II was contiguous with that in the somatosensory cortical areas' layers II-III, which is consistent with one of the major superficial cortical patterns of D1 mRNA and protein expression in mouse. Moreover, the piriform layer II is almost totally composed of D1+ neurons (Huang et al., 1992), and the intercalated nucleus is the major amygdalar locale of D1+ neurons (Weiner et al., 1991). All other CNS areas were examined in multiple coronal and sagittal sections using two different ISH methodologies, including one method for maximum sensitivity (free-floating ISH), and were found to exhibit no detectable CT expression. CT mRNA was thus not detectable above background in the other D1+ CNS regions, including other cortical regions, deeper cortical layers, or the striatum (Fig. 3), or elsewhere in the CNS (data not shown). Outside the CNS, CT mRNA was not detected in lung, liver, spleen, or heart but, consistent with previous reports on D1 expression (O'Connell et al., 1995), was detected in kidney by Northern analysis (data not shown). It is unlikely that CT expression in the kidney contributes to the mouse's behavioral phenotype. We were unable to determine the pattern of D1CT transgene expression in the CNS of the other transgene-expressing strain represented by the D1CT-11 founder, because its brain was isolated unperfused during oocyteremoval surgery for attempted in vitro fertilization. Because of the D1CT-7 strain's regionally restricted pattern of CT expression in a subset of $\mathrm{D} 1+$ neurons of the CNS, these mice provide an opportunity to examine the behavioral roles of $\mathrm{D} 1+$ neurons 

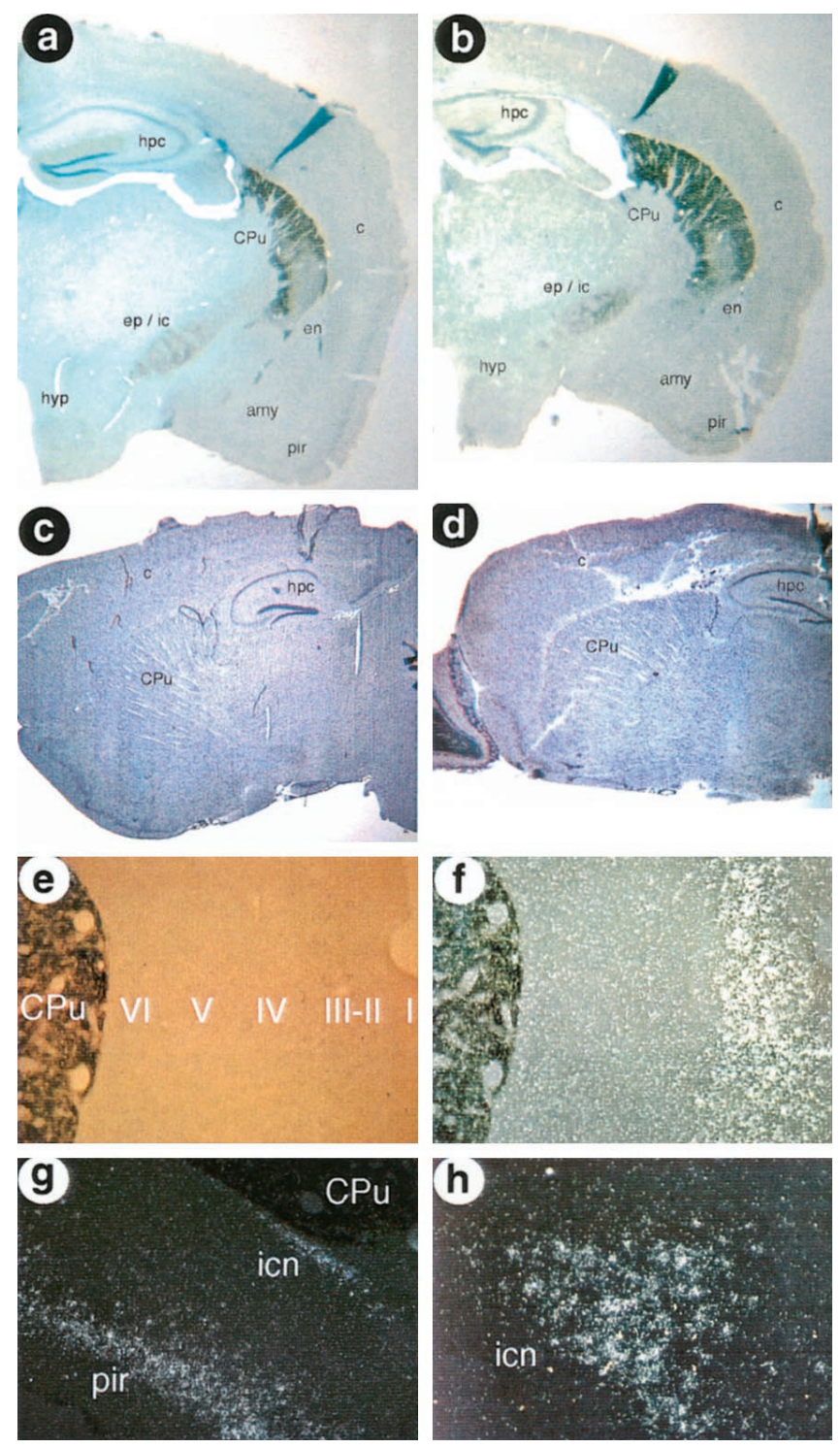

Figure 3. D1CT transgene expression and D1 receptor and CNS neuroarchitecture of D1CT-7 mice. $a, b$, Bright-field view of ICC staining for the D1 receptor (dark staining with blue Nissl counterstain) in coronal brain sections, indicating no discernible changes in D1 receptor distribution, neuroanatomy, or density between control nontransgenic $(a)$ and D1CT-7 $(b)$ mice. $c, d$, Bright-field view of Nissl-stained sagittal brain sections, indicating no discernible changes in CNS morphology or neuron number between control nontransgenic $(c)$ and D1CT-7 $(d)$ mice. $e$, Bright-field view of ICC staining for the D1 receptor (dark staining) in a coronal section of the somatosensory and insular cortex [right (ventral to dorsal), insular, S2, S1] and the caudate-putamen (left), showing extensive D1 receptor expression in the caudate-putamen and less extensive but evident D1 receptor expression in the somatosensory and insular cortex, predominantly in layers II-III. $f$, Dark-field view of ISH staining for the presence of CT mRNA (light grains) performed on the same section shown in $e$, showing colocalization of CT mRNA with D1 receptor staining in the somatosensory and insular cortex layers II-III but not in the caudate-putamen. $g$, Dark-field view of ISH staining, detecting the presence of CT mRNA (light grains) in the piriform cortex layer II and the intercalated nucleus of the amygdala, regions that are also positive for D1 receptor mRNA and protein (data not shown). $h$, Higher magnification dark-field view of ISH staining of CT mRNA (light grains) in the intercalated nucleus of the amygdala in a coronal section parallel to that in $g$. Control nontransgenic littermates exhibit indistinguishable D1 receptor and Nissl staining in these regions and other CNS regions but no CT mRNA ISH staining (data not shown). This regionally restricted pattern of CT ISH staining to the areas shown was consistent between different

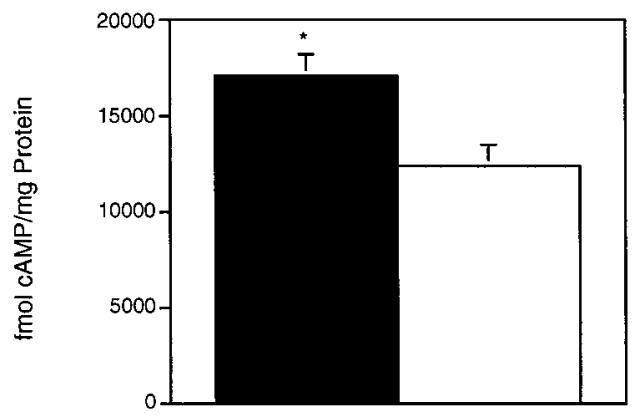

Figure 4. Elevated cAMP levels in CT + CNS regions of D1CT-7 mice. The mean cAMP content (femtomoles of cAMP per milligram of protein) of extracts prepared from whole dissected somatosensory and piriform cortex is shown. Filled bar, D1CT-7 mice; open bar, control nontransgenic littermate mice; error bars indicate $+\mathrm{SEM} ; n=6$ mice per group; * $p<0.05$ using Student's $t$ test.

located in cortical and limbic regions apart from their role in the basal ganglia.

\section{Proximal biochemical effects of D1CT transgene expression}

To determine whether expression of the CT transgene led as predicted to an elevation of cAMP levels in CT-expressing brain regions in the D1CT mice, we performed cAMP radioimmunoassay on extracts of whole dissected piriform and somatosensory cortex (D1CT-7 strain). Because of its intercalated nature, intact dissection of the intercalated nucleus of the amygdala was not feasible. The cAMP content of piriform and somatosensory cortex extracts was elevated $38 \%$ in the D1CT-7 mice relative to that in control siblings (Fig. 4), consistent with the reported action of CT protein to activate adenylyl cyclase chronically (Gill and Meren, 1978; Zeiger et al., 1997). Although the observed increase in cortical cAMP content in our study is lower than the severalfold increases seen in these previous reports, it should be noted that just a fraction of the cells in the dissected cortex tissue were CT-expressing cells, which represent D1+ layer II-III excitatory projection neurons (Huang et al., 1992; Bergson et al., 1995; Gaspar et al., 1995) but do not include D1-negative layer II-III inhibitory interneurons (Grobin and Deutch, 1998), any neurons in deeper cortical layers, or any cortical glial cells. In contrast, the previous studies examined cAMP increases within more homogeneous cultured cells or endocrine glands, in which all or most of the cells were exposed to CT.

To determine whether the D1CT transgene was having a deleterious effect on either CNS development or survival of D1+ neurons, we examined CNS sections of D1CT-7, D1CT-11, and control nontransgenic mice by D1 receptor immunocytochemistry and/or Nissl staining. All transgenic and control mouse brains were anatomically normal by gross dissection (D1CT-7; $n=19$ ). D1CT-7 mice showed no discernible change in D1 receptor neuroanatomical distribution or density by D1 receptor immunocytochemical staining or in general CNS morphology or neuron number by Nissl staining in either transgene-expressing or other

\section{$\leftarrow$}

D1CT-7 mice, reflecting the identical behavior of the animals of this line. For ISH, $n=3$ per group; for Nissl, $n=4$ per group; and for D1 receptor ICC, $n=2$ per group. amy, Amygdala; $c$, cortex; $C P u$, caudate-putamen; $e n$, endopiriform nucleus; $e p / i c$, entopeduncular nucleus/internal capsule; $h p c$, hippocampus; hyp, hypothalamus; icn, intercalated nucleus of the amygdala; pir, piriform cortex; $I-V I$, somatosensory cortical layers. 
Figure 5. D1CT-7 mice nonaggressively bite their sibling cage mates. $a$, Sibling missing tail. $b$, Sibling missing ears. $c$, The fraction of recorded audible distress vocalizations occurring while a D1CT-7 or control nontransgenic littermate mouse was observed to have its snout in contact with another mouse. Filled bar, D1CT-7 mice; open bar, control nontransgenic littermate mice; number of observation periods per mouse $=$ $112 ; n=3$ mice per group; error bars indicate $+\mathrm{SEM} ; * * * p<0.001$ by Student's $t$ test. $d$, Resident-intruder aggression assay. Shown are the mean number of attacks by resident D1CT-7 transgenic mice or control nontransgenic littermates on an intruder mouse within 3 min. Filled bar, D1CT-7 mice; open bar, control nontransgenic littermate mice; $n=9$ mice per group; error bars indicate + SEM; ${ }^{*} p<0.05$ using repeated measures ANOVA $\left[F_{(1,7)}=\right.$ $6.798 ; p=0.035]$. The outcome of the parametric analysis was confirmed by a Wilcoxon signed rank test $(Z=-2.375$; $p=0.018) . e$, Representative transgenic lineage of D1CT-7 mouse-biting behavior. Dark symbols, D1CT mice; open symbols, control nontransgenic littermate mice; gray symbol, mouse that died before determination of transgenic status; square, male; circle, female; /, bitten mouse; $B$, biting mouse (determined either by direct observation or by observation that it was the only unbitten mouse in the cage); $(B)$, biting mouse
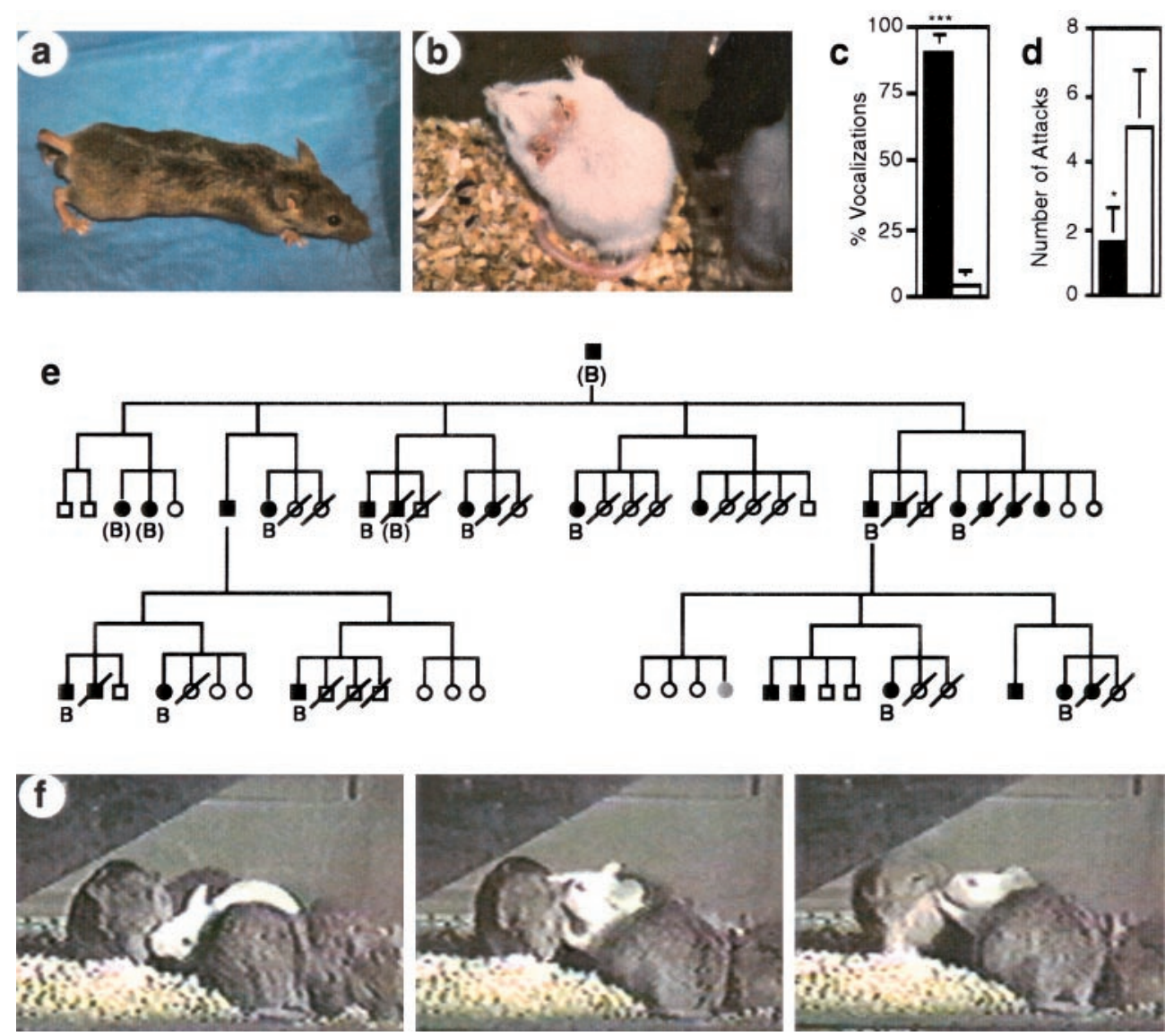

(shown to bite mate when placed in a breeding cage). f, Sequential frames extracted from a video-recording of a D1CT-7 mouse (white) repeatedly biting a sibling mouse (agouti) during conspecific grooming rather than aggressive attack. Left, Initial grooming at face, 0 sec. Middle, Grooming behind head after several bites, $12 \mathrm{sec}$. Right, Bite and startle/vocalization of sibling, $12.5 \mathrm{sec}$. Biting while grooming continues in spite of vocalizations by the bitten mouse.

CNS regions (Fig. 3). Similarly, Nissl staining of an unperfused brain hemisphere isolated from the other transgene-expressing founder, D1CT-11, revealed no discernible change in CNS morphology or neuron number (data not shown). Hence, D1CT transgene expression did not significantly affect the development or survival of D1+ neurons or other neurons, consistent with previous reports that $\mathrm{CT}$ protein is noncytotoxic and nonneurotoxic (Burton et al., 1991, 1998; Wogensen et al., 1993; Zeiger et al., 1997).

\section{D1CT-7 mice exhibit nonaggressive, repetitive biting of siblings}

A surprising trait of severe sib-biting behavior was observed in D1CT-7 mice beginning with the F0 (founder) generation and persisting in all subsequent Balb/c-inbred generations (F1-F8). This behavior was much more severe than normal dominance biting in that cage mates of D1CT-7 mice were often found to be missing ears and/or tails (Fig. 5a,b). Lineage analysis revealed that $100 \%$ of the putative biting mice (either those who remained unwounded in cages in which all other cage mates had been wounded or those who were directly observed to bite their siblings or mates) were D1CT-7 transgenics (Fig. 5e). Furthermore, nearly $100 \%$ of audible distress vocalizations occurred when the snouts of D1CT-7 mice, rather than that of control mice, were observed to be in contact with the tail, head, or flank of sibling mice (Fig. $5 c$ ). Based on the presumption that an association of snout contact and distress vocalization with associated wounding signifies biting, these data indicated that the wounded and/or missing ears and tails of siblings were indeed attributable to biting by D1CT-7 mice.

Intriguingly, female as well as male D1CT-7 mice engaged in this biting behavior, whereas biting by other genetically engineered mouse mutants is typically male-specific and interpreted as being caused by aggression (for review, see Hen, 1996). In contrast, observed D1CT-7 mouse biting did not occur during aggressive displays or fighting but instead occurred in a repeating manner during episodes of social grooming (Fig. 5f). Also, biting around the face and head, seen in this study, is not typically a feature of agonistic encounters (Alleva, 1993). Lastly, this biting behavior began when the mice were $<3$ weeks old, an age at which typical aggression and dominance usually have not yet been established (Alleva, 1993). Because of these reasons, we conjectured that D1CT-7-biting behavior may not be attributable to "typical" aggression. This was confirmed in a resident-intruder aggression assay, which revealed that resident D1CT-7 mice attacked intruder mice less often than did their nontransgenic siblings (Fig. $5 d$ ) and exhibited a significantly longer latency to the first attack $(130.3 \pm 22.1 \mathrm{sec}$ for D1CT vs $92.8 \pm 23.6 \mathrm{sec}$ for control; $n=9 ; Z=-1.96 ; p=0.0499$ using Wilcoxon signed rank test). Therefore, in spite of their severe biting behavior, D1CT-7 mice are actually less aggressive than are their nontransgenic siblings. The absence of increased aggression in the D1CT-7 mice was confirmed in a repetition of this assay (data not shown). 


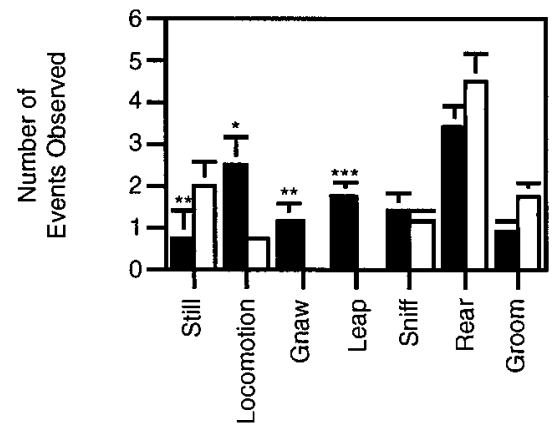

Figure 6. Increased locomotion, gnawing, and leaping in D1CT-7 mice. A bar graph of the mean number of observed behaviors that were $>3$ consecutive seconds in duration (Fray et al., 1980) is shown. Filled bars, D1CT-7 mice; open bars, control nontransgenic littermate mice; $n=14$ mice per group; error bars indicate $+\mathrm{SEM} ;{ }^{*} p<0.05,{ }^{* *} p<0.01$, and ${ }^{* * *} p<0.001$ using Student's $t$ test. MANOVA of the predicted dopaminergically induced behaviors consisting of the dependent variables locomotion, rear, sniff, gnaw, groom, and leap indicated a significant difference between transgenic and control nontransgenic littermates $\left[F_{(6,21)}=\right.$ 5.214; $p=0.002]$. Therefore the aforementioned independent analysis of each variable was justified.

The above data showed that D1CT-7 transgenic mice engage in severe, grooming-associated repetitive biting that is nonaggressive. To test whether their biting was attributable to an olfactory sensory deficit, we determined whether they exhibited normal olfactory discrimination and recognition capabilities. D1CT-7 mice were capable of locating even minute quantities of aromatic food hidden under their cage bedding in the same number of seconds as were control nontransgenic siblings and, like control siblings, exhibited aversion to novel citrus aroma (data not shown). Moreover, D1CT-7 mice exhibited olfactory recognition (anal sniffing) behavior and also responded to visual, tactile, and auditory stimuli. These observations suggest that the repetitivebiting behavior of the D1CT-7 mouse strain is likely to be compulsive rather than caused by an olfactory or other sensory deficit.

\section{D1CT-7 mice exhibit both stereotypies and complex behavioral repetition and perseverance}

In addition to observing compulsive-biting behavior, we examined D1CT-7 mice for the presence of so-called stereotypic behaviors, which can be induced in normal rodents by dopaminergic drugs (Fray et al., 1980; Ming et al., 1994; Xu et al., 1994). Using a time-sampling assay (Fray et al., 1980), we found D1CT-7 mice to exhibit increased locomotion, wall leaping, and gnawing (Fig. 6).

To obtain a more precise understanding of the behavioral abnormalities exhibited by the D1CT-7 mice, we also measured their total behavior in real time, by logging and graphically depicting the duration and frequency of each behavioral state using "behavioral waveform display," a method to detect abnormal behaviors not detectable by time-sampling assays (Campbell et al., 1998). Confirming the results of the time-sampling assay, we found by waveform display analysis that D1CT-7 mice exhibit repetitive locomotion and repetitive leaping, whereas leaping was entirely absent in nontransgenic siblings (Fig. 7). Observation of these behavioral abnormalities of D1CT-7 mice, as well as those described below, was replicable over numerous trials performed on subsequent Balb/c-inbred generations (F1-F6).

Interestingly, D1CT-7 mice also would routinely "lock in" on any given normal behavior and engage in it for extended periods.
In other words, the mice exhibited perseverant episodes of any and all normal behaviors, while maintaining a full behavioral repertoire (Fig. $7 b, c$ ). This complex behavioral abnormality is distinct from the simple stereotypies and restricted behavioral repertoire in other animal models of compulsion, such as mice given dopaminergic drugs (Fray et al., 1980; Xu et al., 1994; Campbell et al., 1998). The behavioral perseverance of the D1CT-7 mice consisted of long-duration episodes of stationary single-state behaviors (eating, drinking, self-grooming, grooming others, and digging) and of long-duration episodes of reiterated locomotor-dependent (two-state) behaviors [e.g., locomote-dig (forage) and locomote-rear (explore)]. The type of perseverant behavior varied between different observations of individual D1CT-7 mice, as well as between different D1CT-7 mice (Fig. $7 b, c)$. The elongation of average behavioral duration in D1CT-7 mice was approximately threefold that of control mice (Fig. 7a,d). This behavioral perseverance was not caused simply by increased locomotion or hyperactivity, because the average duration of stationary behaviors in these mice was also threefold greater (Fig. $7 e$ ). Moreover, hyperactivity induced by dopaminergic drugs like cocaine is typically associated with shortened, not elongated, individual behaviors (Campbell et al., 1998). In this regard, cocaine actually masks the unique compulsions of the D1CT-7 mice while inducing hyperactive and stereotypic behaviors identical to those of cocaine-treated control mice (K. M. Campbell, M. J. McGrath, and F. H. Burton, unpublished results). This suggests that the transgene-induced compulsions differ in their neuroanatomical origin or circuitry from general "dopaminergic" hyperactivity and stereotypies. Thus our data cumulatively indicate that D1CT-7 mice exhibit unique complex compulsions including grooming-associated biting, compulsive leaping, and episodes of perseverance or repetition of any and all normal behaviors.

\section{DISCUSSION}

\section{Efficacy of the D1CT transgene}

We generated transgenic mouse strains that express a neuropotentiating transgene, an intracellular form of $\mathrm{CT}$, from the dopamine D1 receptor promoter. Because the CT transgene used in this study chronically stimulates $\mathrm{G}_{\mathrm{s}}$ activity, $\mathrm{G}_{\mathrm{s}}$-coupled cAMP levels, and cAMP-dependent cellular changes in cultured cells and intact animals (Burton et al., 1991; Zeiger et al., 1997) and causes permanent neuronal excitation-associated neurological and behavioral changes in mice (Burton et al., 1998), targeted expression of this transgene in D1+ neuron subtypes may cause more pronounced and chronic activation of D1+ neurons than would traditional D1-agonist-based approaches. Because D1+ neurons express many other classes of $\mathrm{G}_{\mathrm{s}}$-coupled receptors, activation of D1 receptors themselves may not be sufficient to cause pronounced and chronic stimulation of the neurons that carry them and may normally require concomitant activation of other coexpressed receptors (Nestler, 1997). Conversely, CT (which irreversibly activates all $\mathrm{G}_{\mathrm{s}}$ molecules normally coupled to many types of receptors), as well as activated adenylyl cyclase and cAMP analogs, effectively enhances neurotransmitter release in response to afferent stimuli, in both D1+ and other neurons (Cunningham and Kelley, 1993; Geller et al., 1993; HernandezLopez et al., 1997). Furthermore, unlike the stimulatory effects of the D1 receptor, whose activity is susceptible to tolerancesubserving mechanisms such as feedback inhibition and downregulation by coexpressed or presynaptic receptors (Winkler et al., 1988; Lidow and Goldman-Rakic, 1994; Lidow et al., 1997; 
a

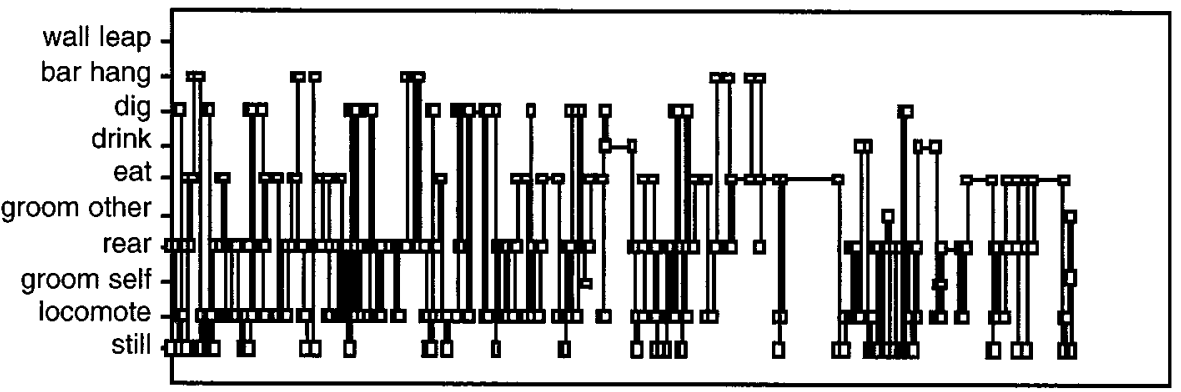

b

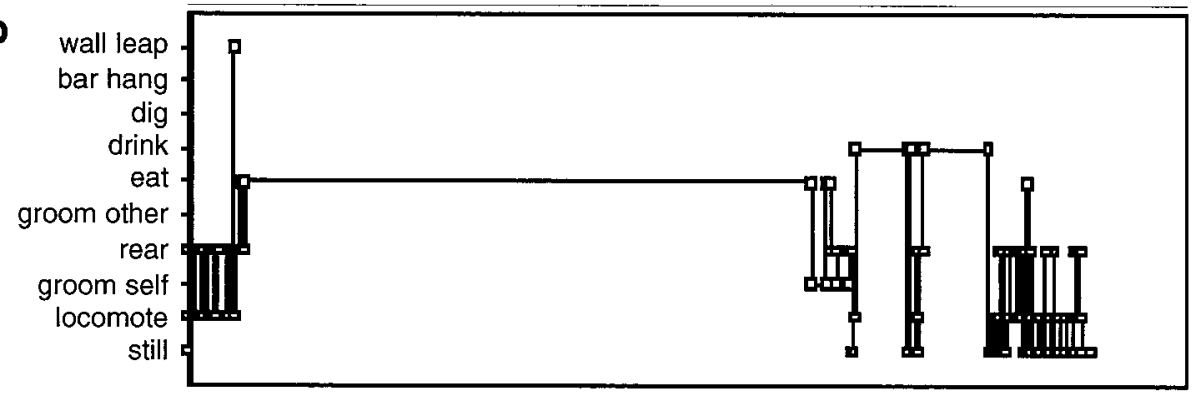

C

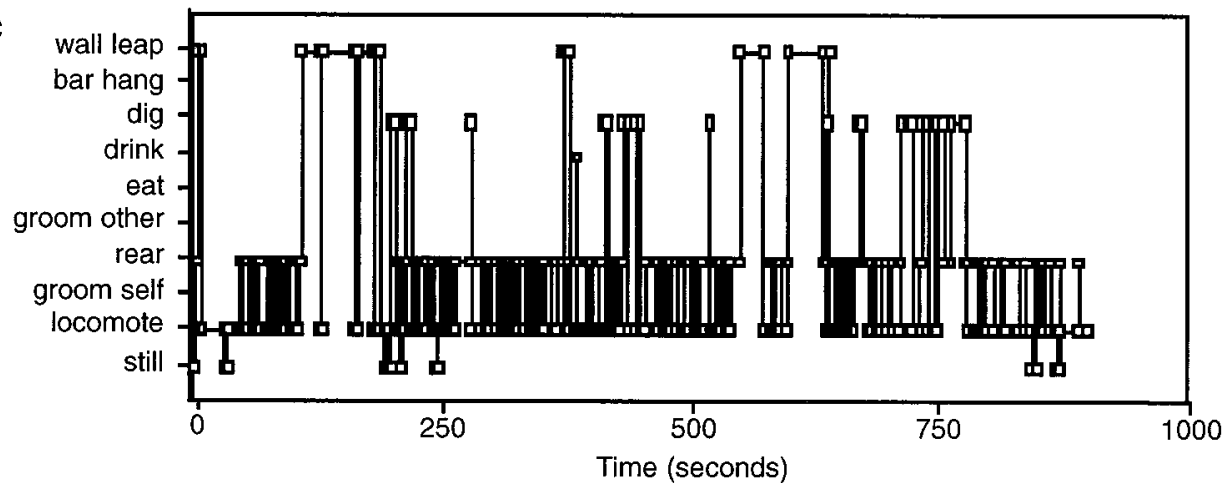

d

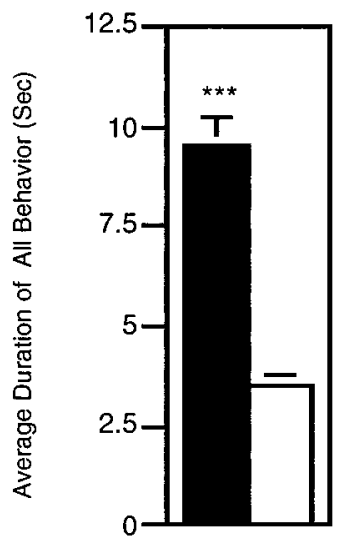

$\mathbf{e}$

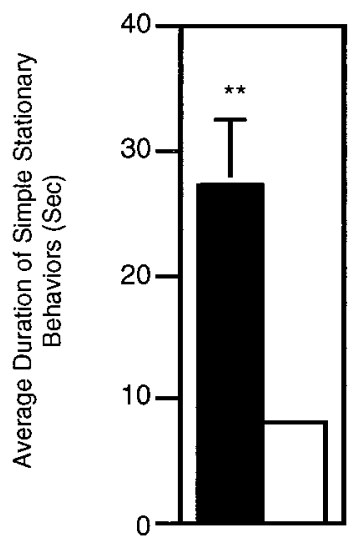

Figure 7. Perseverative (long-duration) and repetitive behaviors in D1CT-7 mice. $a-c$, Representative behavioral waveform displays (Campbell et al., 1998) of normal behavior in individual control nontransgenic littermate mouse $(a)$ and of perseverative behavior $(b$; in this instance, eating) or repetitive behavior ( $c$; in this instance, locomote-rear) in D1CT-7 mice. The type of perseverative or repetitive behavior exhibited by the D1CT-7 mice continuously varies in each individual. In this display, behavioral activities analyzed are on the $y$-axis, whereas time is on the $x$-axis. Thus, vertical lines represent transitions from one behavior to another, whereas horizontal lines represent the duration of each behavior. Periods of rapid behavioral switching appear as condensed vertical lines or bars. $d, e$, Comparison of the mean duration of all behaviors $(d)$ or of nonlocomotor behaviors $(e)$ exhibited by D1CT-7 and control mice. Filled bars, D1CT-7 mice; open bars, control nontransgenic littermate mice; $n=6$ mice per group; error bars indicate + SEM; ${ }^{* *} p<0.01$ and ${ }^{* * *} p<0.001$ using Student's $t$ test. $d$ shows the mean duration of all behaviors, either simple stationary (1-state) or complex locomotor-dependent (2-state), observed within a $30 \mathrm{~min}$ period, whereas $e$ shows the mean duration of all simple stationary (nonlocomotor-dependent) behaviors (i.e., eat, drink, self-groom, groom other, rear, dig, and bar hang) observed within a 30 min period.

Tomic et al., 1997), the stimulatory effects of CT are not reversed by feedback mechanisms (Gill and Meren, 1978; Landis et al., 1989; Burton et al., 1991, 1998; Spiegel, 1996; Zeiger et al., 1997). Because CT and elevated cAMP levels permanently potentiate neuron excitability (Geller et al., 1993; Hernandez-Lopez et al., 1997) and induce excitation-associated neurological and behavioral changes (Cunningham and Kelley, 1993; Burton et al., 1998), similar excitatory signaling changes should be induced within the CT-expressing neurons of D1CT-7 mice. Consistent with this hypothesis, transgene-expressing cortical regions in D1CT-7 mice exhibited elevated cAMP levels compared with the same regions in control nontransgenic mice.

\section{D1CT phenotype is correlated with transgene expression}

Several lines of evidence indicate that the phenotypes of the D1CT mice are caused by transgene expression of CT in D1+ neuron subpopulations rather than by random insertional mutagenesis during transgene integration. First, only the two founder strains that expressed their D1CT transgene exhibited psychomotor behavioral abnormalities. Second, because the D1CT mice in this study were heterozygous for the transgene, it is unlikely that a random gene knock-out caused the D1CT-11 and D1CT-7 mouse psychomotor disorders. This is because the putative heterozygous mutated genes in both transgenic strains would have to exhibit relatively rare haploid insufficiency. Third, D1CT mice (D1CT-7 strain) exhibited a predicted direct consequence of transgenic CT expression, elevated cortical cAMP levels. Lastly, D1CT mice (D1CT-7 strain) are resistant to the cataleptic action of D1 but not D2 receptor antagonists (Campbell, McGrath, and Burton, unpublished results), even though their striatal D1 receptor expression is normal. Both elevated cortical cAMP levels (as discussed previously) and differential 
striatal resistance to D1 and D2 antagonists (as discussed below) are predicted consequences of CT potentiation of D1+ corticallimbic neurons thought to induce excitatory glutamate output but are an unlikely consequence of random insertional mutagenesis.

\section{Regional restriction of D1CT expression}

Regional restriction of transgene expression has been used to confer hippocampal-restricted CaMKII+ neuron-specific expression of either constitutively active, calcium-independent CaMKII (Bach et al., 1995; Mayford et al., 1995, 1996; Rotenberg et al., 1996) or the Cre recombinase to knock out the NMDAR1 gene selectively in the hippocampal CA1 region (Tsien et al., 1996b), whereas here it has been used to target D1+ neurostimulatory $\mathrm{CT}$ transgene expression regionally. In D1CT-7 mice, we detected regionally restricted $\mathrm{CT}$ transgene coexpression with D1 protein within the piriform cortex layer II, layers II-III of somatosensory cortical areas, and the intercalated nucleus (ICN) of the amygdala, areas known to express D1 receptor mRNA and protein. Because of their regional restriction of transgene expression, D1CT-7 mice permit examination of the behavioral role of $\mathrm{D} 1+$ neurons in these particular cortical and amygdalar regions, apart from the role of D1+ neurons in the basal ganglia or other brain regions. Moreover, as suggested by the distinct but overlapping hyperlocomotor and hyperreactive psychomotor abnormality of the D1CT-11 mouse and by the lethal tremor and/or psychomotor abnormalities induced by broader CNS expression of CT in neuron-specific enolase-CT (NSECT) transgenic mice (Burton et al., 1998), future studies of additional D1CT transgenic strains, which likely will have different regionally restricted patterns of CT transgene expression, should prove useful as a tool to query the in vivo role of other $\mathrm{D} 1+$ neuron subpopulations.

\section{Putative neuroanatomical basis for D1CT mice compulsive abnormalities}

The subset of cortical and limbic neurons chronically potentiated in D1CT-7 mice is thought to induce glutamatergic output to the striatum. D1+ neurons in layers II-III of somatosensory cortical areas and the piriform layer II are glutamatergic neurons that stimulate lateral cortical areas as well as deeper-layer corticostriatal glutamatergic neurotransmission (Yamamoto et al., 1990; Huang et al., 1992; Kaneko et al., 1994; Bergson et al., 1995; Gaspar et al., 1995; Grobin and Deutch, 1998). The piriform and its laterally stimulated prefrontal areas (Morecraft et al., 1992; Barbas, 1993) selectively innervate the ventral striatum and nucleus accumbens, regions that mediate general locomotor hyperactivation and gnawing, two of the behaviors elicited in D1CT-7 mice (McGeorge and Faull, 1989; Delfs and Kelly, 1990; Berendse et al., 1992). Amygdalar ICN neurons GABAergically regulate excitatory output from the central and basolateral amygdaloid nuclei, which supply the majority of limbic connections to prefrontal cortical areas and the ventral striatum (McDonald, 1987; Scibilia et al., 1992; McDonald and Augustine, 1993; Gerfen and Wilson, 1996). Because electrical stimulation of the ICN enhances startle behavior (Rosen and Davis, 1988), D1CT potentiation of these ICN neurons may similarly stimulate corticostriatal and striatal activity. Also, the somatosensory cortex innervates more dorsal regions of the striatum (Gerfen and Wilson, 1996), a subset of which can induce orofacial activity (Spooren et al., 1991).

In agreement with the idea that chronic potentiation of these $\mathrm{D} 1+$ neurons in D1CT-7 mice increases glutamate output to the striatum, D1CT-7 mice were found to be resistant to the catalep- tic effect of D1 antagonists and supersensitive to D2 antagonists (Campbell, McGrath, and Burton, unpublished results). Because striatal D1 receptors increase while striatal D2 receptors decrease afferent glutamate's effects on the direct and indirect striatal motor pathways, respectively (Cepeda et al., 1993), excessive glutamatergic excitation of the striatum would be predicted to reduce motor dependence on D1 receptors and to increase motor dependence on $\mathrm{D} 2$ receptors.

Additionally, seizures originating in limbic areas can similarly induce oral and motor compulsive behaviors (Zhang et al., 1997). However, because D1CT-7 mouse compulsions do not occur as part of the staged behavioral patterns of limbic seizures and because D1CT-7 mice also exhibit compulsions unrelated to seizure activity, their repetitive gnawing and leaping are unlikely to be caused by limbic seizure activity itself but rather may result from activation of D1+ neurons that could also be stimulated during nonspecific limbic seizure propagation.

The possible neuroanatomical basis of the episodic perseverance or repetition of any and all behaviors in D1CT-7 mice is not known, but we predict that, like their biting during grooming and their leaping, it could be a consequence of neurostimulation of regions also hyperactive in $\mathrm{OCD}$, including the amygdala and somatosensory/insular and orbitofrontal (OFC) cortical regions (Horwitz et al., 1991; Breiter et al., 1996) that in OCD are similarly thought to hyperstimulate the striatum glutamatergically (Bernstein et al., 1975; Kurlan et al., 1990; Breiter et al., 1996). The potentiated amygdalar, somatosensory/insular, and piriform D1+ neurons of D1CT-7 mice are thought to excite directly or indirectly not only deep-layer striatally projecting cortical neurons and the striatum but also the OFC among other prefrontal regions (McDonald, 1987; Morecraft et al., 1992; Barbas, 1993). Furthermore, not only do the compulsions of D1CT-7 mice and disorders like OCD involve grooming-associated biting and unusual movements, but their behavioral perseverance is similar in its complexity - it does not resemble, for example, the simple motor hyperactivity and specific stereotypies caused by broadacting dopaminergic drugs such as cocaine (Campbell, McGrath, and Burton, unpublished results). Thus, the generalized behavioral perseverance and repetition in D1CT-7 mice as well as their biting and leaping compulsions may be a consequence of neurostimulation within some of the integrative cortical regions also hyperstimulated in OCD. Alternatively, the behavioral abnormalities of D1CT-7 mice could be the consequence of transgenically potentiated excitatory projections to the striatum overriding normally operative prefrontal control mechanisms. Future analysis of regional neurotransmitter and metabolic activity changes in these mice may shed light on the selective roles of subpopulations of $\mathrm{D} 1+$ neurons within the cortex and limbic system in the induction of chronic, complex compulsions.

\section{REFERENCES}

Abel T, Nguyen PV, Borad M, Deuel TA, Kandel ER, Bourtchouladze R (1997) Genetic demonstration of a role for PKA in the late phase of LTP and in hippocampus-based long-term memory. Cell 88:615-626.

Alleva E (1993) Assessment of aggressive behavior in rodents. Methods Neurosci 14:111-137.

Ariano MA, Sibley DR (1994) Dopamine receptor distribution in the rat CNS: elucidation using anti-peptide antisera directed against D1A and D3 subtypes. Brain Res 649:95-110.

Bach ME, Hawkins RD, Osman M, Kandel ER, Mayford M (1995) Impairment of spatial but not contextual memory in CaMKII mutant mice with a selective loss of hippocampal LTP in the range of the theta frequency. Cell 81:905-915. 
Bachus SE, Kleinman JE (1996) The neuropathology of schizophrenia. J Clin Psychiatry 57:72-83.

Barbas H (1993) Organization of cortical afferent input to orbitofrontal areas in the rhesus monkey. Neuroscience 56:841-864.

Berendse HW, deGalis GY, Groenewegen HJ (1992) Topographical organization and relationship with ventral striatal compartments of prefrontal corticostriatal projections in the rat. $\mathbf{J}$ Comp Neurol 316:314-347.

Bergson C, Mrzlijak L, Smiley JF, Pappy M, Levenson R, Goldman-Rakic PS (1995) Regional, cellular, and subcellular variations in the distribution of D1 and D5 dopamine receptor in primate brain. J Neurosci 15:7821-7836.

Bernheimer H, Birkmayer W, Hornykiewicz O, Jellinger K, Seitelberger F (1973) Brain dopamine and the syndromes of Parkinson and Huntington. Clinical, morphological, and neurochemical correlations. J Neurol Sci 20:415-455.

Bernstein IC, Callahan WA, Jaranson JM (1975) Lobotomy in private practice. Arch Gen Psychol 32:1041-1047.

Breiter HC, Rauch SL, Kwong KK, Baker JR, Weisskoff RM, Kennedy DN, Kendrick AD, Davis TL, Jiang A, Cohen MS, Stern CE, Belliveau JW, Baer L, O'Sullivan RL, Savage CR, Jenike MA, Rosen BR (1996) Functional magnetic resonance imaging of symptom provocation in obsessive-compulsive disorder. Arch Gen Psychiatry 53:595-606.

Brown AS, Gershon S (1993) Dopamine and depression. J Neural Transm 91:75-109.

Burton FH, Hasel K, Bloom FE, Sutcliffe JG (1991) Pituitary hyperplasia and gigantism in mice caused by a cholera toxin transgene. Nature 350:74-77.

Burton FH, Forss-Petter S, Battenberg E, Bloom FE, Sutcliffe JG (1998) Lethal psychomotor abnormalities in mice caused by a neural cholera toxin transgene. Transgenics 2:249-257.

Campbell KM, Rohland RM, McGrath MJ, Satoskar SD, Burton FH (1998) Detecting complex repetitive or stereotypic behaviors by graphing behavior as a multifrequency waveform. Physiol Behav 64:83-91.

Cepeda C, Buchwald NA, Levine MS (1993) Neuromodulatory actions of dopamine in the neostriatum are dependent on the excitatory amino acid receptor subtypes activated. Proc Natl Acad Sci USA 90:9576-9580.

Connolly JB, Roberts JH, Armstrong JD, Kaiser K, Forte M, Tully T, O'Kane CJ (1996) Associative learning disrupted by impaired Gs signaling in Drosophila mushroom bodies. Science 274:2104-2107.

Cunningham ST, Kelley AE (1993) Hyperactivity and sensitization to psychostimulants following cholera toxin infusion into the nucleus accumbens. J Neurosci 13:2342-2350.

de Lecea L, del Rio JA, Criado JR, Alcantara S, Morales M, Danielson PE, Henriksen SJ, Soriano E, Sutcliffe JG (1997) Cortistatin is expressed in a distinct subset of cortical interneurons. J Neurosci 17:5868-5880.

Delfs JM, Kelly AE (1990) The role of D1 and D2 dopamine receptors in oral stereotypy induced by dopaminergic stimulation of the ventrolateral striatum. Neuroscience 39:59-67.

Fray PJ, Sahakian BJ, Robbins TW, Koob GF, Iversen SD (1980) An observational method for quantifying the behavioral effects of dopamine agonists: contrasting effects of D-amphetamine and apomorphine. Psychopharmacology (Berl) 69:253-259.

Fremeau Jr RT, Duncan GE, Fornaretto MG, Dearry A, Gingrich JA, Breese GR, Caron MG (1991) Localization of D1 dopamine receptor mRNA in brain supports a role in cognitive, affective, and neuroendocrine aspects of dopaminergic neurotransmission. Proc Natl Acad Sci USA 88:37772-37776.

Gaspar P, Bloch B, LeMoine C (1995) D1 and D2 receptor gene expression in the rat frontal cortex: cellular localization in different classes of efferent neurons. Eur J Neurosci 7:1050-1063.

Geller AI, During ML, Haycock JL, Freese A, Neve R (1993) Longterm increases in neurotransmitter release from neuronal cells expressing a constitutively activated adenylate cyclase from a herpes simplex virus type I vector. Proc Natl Acad Sci USA 90:7603-7607.

Gerfen CR, Wilson JW (1996) The basal ganglia. Handbook of Chem Neuroanat 12:371-468.

Gettys TW, Okonogi K, Tarry WC, Johnston J, Horton C, Taylor IL (1990) Elimination of relative rates of cAMP synthesis and degradation in crude membranes of adipocytes treated with hormones. Second Messengers Phosphoproteins 13:37-49.

Gill DM, Meren R (1978) ADP-ribosylation of membrane proteins cat- alyzed by cholera toxin: basis of the action of adenylate cyclase. Proc Natl Acad Sci USA 75:3050-3054.

Grobin AC, Deutch AY (1998) Dopaminergic regulation of extracellular gamma-aminobutyric acid levels in the prefrontal cortex of the rat. J Pharmacol Exp Ther 285:350-357.

Hen R (1996) Mean genes. Neuron 16:17-21.

Hernandez-Lopez S, Bargas J, Surmeier DJ, Reyes A, Galarraga E (1997) D1 receptor activation enhances evoked discharge in neostriatal medium spiny neurons by modulating an L-type $\mathrm{Ca}^{2+}$ conductance. J Neurosci 17:3334-3342.

Horwitz B, Swedo SE, Grady CL, Pietrini P, Schapiro MB, Rapoport JL, Rapoport SI (1991) Cerebral metabolic pattern in obsessivecompulsive disorder: altered intercorrelations between regional rates of glucose utilization. Psychiatry Res 40:221-237.

Huang Q, Zhou D, Chase K, Gusella JF, Aronia N, DiFiglia M (1992) Immunocytochemical localization of the D1 dopamine receptor in rat brain reveals its axonal transport, pre- and postsynaptic localization, and prevalence in the basal ganglia, limbic system and thalamic reticular nucleus. Proc Natl Acad Sci USA 89:11988-11992.

Kaneko T, Caria MA, Asanuma H (1994) Information processing within the motor cortex. II. Intracortical connections between neurons receiving somatosensory cortical input and motor output neurons of the cortex. J Comp Neurol 345:172-184.

Kurlan R, Kersun J, Ballantine HT, Caine ED (1990) Neurosurgical treatment of severe obsessive-compulsive disorder associated with Tourette's syndrome. Mov Disord 5:152-155.

Landis CA, Masters SB, Spada A, Pace AM, Bourne HR, Vallar L (1989) GTPase inhibiting mutations activate the alpha chain of Gs and stimulate adenylyl cyclase in human pituitary tumours. Nature 340:692-696.

Levey AI, Hersch SM, Rye DB, Sunahara RK, Niznik HB, Kitt CA, Price DL, Maggio R, Brann MR, Ciliax BJ (1993) Localization of D1 and D2 dopamine receptors in brain with subtype-specific antibodies. Proc Natl Acad Sci USA 90:8861-8865.

Lidow MS, Goldman-Rakic PS (1994) A common action of clozapine, haloperidol, and remoxipride on D1- and D2-dopaminergic receptors in the primate cerebral cortex. Proc Natl Acad Sci USA 91:4353-4356.

Lidow MS, Elsworth JD, Goldman-Rakic PS (1997) Down-regulation of the D1 and D5 dopamine receptors in the primate prefrontal cortex by chronic treatment with antipsychotic drugs. J Pharmacol Exp Ther 281:597-603.

Mayford M, Wang J, Kandel ER, O’Dell TJ (1995) CaMKII regulates the frequency-response function of hippocampal synapses for the production of both LTD and LTP. Cell 81:891-904.

Mayford M, Bach ME, Huang YY, Wang L, Hawkins RD, Kandel ER (1996) Control of memory formation through regulated expression of a CaMKII transgene. Science 274:1678-1683.

McDonald AJ (1987) Organization of amygdaloid projections to the mediodorsal thalamus and prefrontal cortex: a fluorescent retrograde transport study in the rat. J Comp Neurol 261:46-58.

McDonald AJ, Augustine JR (1993) Localization of GABA-like immunoreactivity in the monkey amygdala. Neuroscience 52:281-294.

McDougle CJ, Goodman WK, Price LH (1994) Dopamine antagonists in tic-related and psychotic spectrum obsessive-compulsive disorder. $\mathrm{J}$ Clin Psychiatry 55:24-31.

McGeorge AJ, Faull RLM (1989) The organization of the projection from the cerebral cortex to the striatum of the rat. Neuroscience 29:503-537.

Ming X, Moratalla R, Gold LH, Hiroi N, Koob GF, Graybiel AM, Tonegawa S (1994) Dopamine D1 receptor mutant mice are deficient in striatal expression of dynorphin and dopamine-mediated behavioral responses. Cell 79:729-742.

Morecraft RJ, Geula C, Mesulam MM (1992) Cytoarchitecture and neural afferents of orbitofrontal cortex in the brain of the monkey. J Comp Neurol 323:341-358.

Nestler EJ (1997) Schizophrenia: an emerging pathophysiology (news and views). Nature 385:578-579.

O'Connell DP, Botkin SJ, Ramos SI, Sibley DR, Ariano MA, Felder RA, Carey RM (1995) Localization of dopamine D1A receptor proteins in rat kidneys. Am J Physiol 268:1185-1197.

Ritz MC, Kuhar MJ (1993) Psychostimulant drugs and a dopamine hypothesis regarding addiction: update on recent research. Biochem Soc Symp 59:51-64.

Rosen JB, Davis M (1988) Enhancement of acoustic startle by electrical stimulation of the amygdala. Behav Neurosci 102:195-202, 324. 
Rotenberg A, Mayford M, Hawkins RD, Kandel ER, Muller RU (1996) Mice expressing activated CaMKII lack low frequency LTP and do not form stable place cells in the CA1 region of the hippocampus. Cell 87:1351-1361.

Scibilia RJ, Lachowicz JE, Kilts CD (1992) Topographic nonoverlapping distribution of D1 and D2 dopamine receptors in the amygdaloid nuclear complex of the rat brain. Synapse 11:146-154.

Severynse DM, Colapietro A, Box TL, Caron MG (1995) The human $\mathrm{D}_{1 \mathrm{~A}}$ dopamine receptor gene promoter directs expression of a reporter gene to the central nervous system in transgenic mice. Mol Brain Res 30:336-346.

Spiegel AM (1996) Defects in G protein-coupled signal transduction in human disease. Annu Rev Physiol 58:143-170.

Spooren WPJM, Groenewegen HJ, Cools AR (1991) Subregions of the caudate nucleus and their in- and output channels in oro-facial dyskinesia: a behavioral and retrograde tracing study in the cat. Brain Res 539:85-93.

Tomic M, Vukosavic S, Joksimovic J (1997) Acute amphetamine and/or phencyclidine effects on the dopamine receptor specific binding in the rat brain. Eur Neuropsychopharmacol 7:295-301.

Tsien JZ, Chen DF, Gerber D, Tom C, Mercer EH, Anderson DJ, Mayford M, Kandel ER, Tonegawa S (1996a) Subregion- and cell type-restricted gene knockout in mouse brain. Cell 87:1317-1326.

Tsien JZ, Huerta PT, Tonegawa S (1996b) The essential role of hippocampal CA1 NMDA receptor-dependent synaptic plasticity in spatial memory. Cell 87:1327-1338.
Walseth TF, Zhang HJ, Olson LK, Schroeder WA, Robertson RP (1989) Increase in Gs and cyclic AMP generation in HIT cells. J Biol Chem 264:21106-21111.

Weiner DM, Levey AI, Sunahara RK, Niznik HB, O'Dowd BF, Seeman P, Brann MR (1991) D1 and D2 dopamine receptor mRNA in rat brain. Proc Natl Acad Sci USA 88:1859-1863.

Winkler JD, Callison K, Cass SA, Weiss B (1988) Selective downregulation of D1 dopamine mediated rotational behavior in supersensitive mice. Neuropharmacology 27:439-442.

Wogensen L, Ma YH, Grodsky GM, Robertson RP, Burton FH, Sutcliffe JG, Sarvetnick N (1993) Functional effects of transgenic expression of cholera toxin in pancreatic beta-cells. Mol Cell Endocrinol 98:33-42.

Xu M, Hu XT, Cooper DC, Moratalla R, Graybiel AM, White FJ, Tonegawa S (1994) Elimination of cocaine-induced hyperactivity and dopamine receptor-mediated neurophysiological effects in dopamine D1 receptor mutant mice. Cell 79:945-955.

Yamamoto T, Samejima A, Oka H (1990) The mode of synaptic activation of pyramidal neurons in the cat primary somatosensory cortex: an intracellular HRP study. Exp Brain Res 80:12-22.

Zeiger MA, Motoyasu S, Gusev Y, Westra WH, Takiyama Y, Dooley WZ, Kohn LD, Levine MA (1997) Thyroid-specific expression of cholera toxin A1 subunit causes thyroid hyperplasia and hyperthyroidism in transgenic mice. Endocrinology 138:3133-3140.

Zhang X, Gelowitz DL, Lai CT, Boulton AA, Yu PH (1997) Gradation of kainic acid-induced rat limbic seizures and expression of hippocampal heat shock protein-70. Eur J Neurosci 9:760-769. 